\title{
The Case of Qualitative Genetics in Fish
}

\author{
Safaa Tariq \\ Department of Biology, Faculty of Science and Health, Koya University, Iraq
}

\begin{abstract}
Character inheritance or heredity is the inheritance of traits from parents to their children (offspring). The event or process by which a cell of an organism tends to become or possess the characteristics of its parents. The discovery of recombinant DNA opened up developments in genetic engineering. Genetic engineering technology provides a lot of hope for us in various areas of need including gene therapy efforts. Inheritance is the traits or traits of living things that are passed down from generation to generation or passed down from parent to offspring. The traits of a living being are inherited through male sex cells and female sex cells. Normal pigmented goldfish are mated with yellow-striped goldfish on the dorsal spine to produce $100 \%$ fish with yellow lines on the dorsal spine.
\end{abstract}

Keywords: Fish, DNA, Qualitative Genetics

Received : August 17, 2020

Received in Revised: August 25, 2020

Accepted: August 28, 2020

\section{Introduction}

Genetics is the study of various aspects related to the inheritance of traits and variations in traits in organisms and sub-organisms (such as viruses and prions) (Chabris, 2015; Morange, Suchon \& Trégouët, 2015; Snustad \& Simmons, 2015). The principle of genetics also needs to be mastered when studying a person's psychological or nervous traits which are determined by hereditary traits, for example the excess of one type of chromosome which is related to mental disorders which results in a person being asocial and criminal (Snustad \& Simmons, 2015). Genetics has a very broad scope, which is both academic and practical, including, among other things, the role of chromosomes, the inheritance of genetic and anthropological traits, chromosomal abnormalities, inherited metabolic errors and incompatibilities in organ transplants Genes as hereditary factors are stored in chromosomes, namely in the beads are called the chromoter or nucleosome of the chromonema (Martínez-Romero \& CaballeroMellado, 1996).

Character inheritance or heredity is the inheritance of traits from parents to their children (offspring). The event or process by which a cell of an organism tends to become or possess the characteristics of its parents. Through heredity, individual variations will arise which accumulate and cause several species to undergo evolution. It can be interpreted that the inheritance of traits is like the inheritance of characters from parent to offspring by means of genes (DNA). Heritable traits are known to continue from one generation to the next through DNA, which is a long polymer molecule composed of 4 types of bases (Ashwell, Van Tassell \& Sonstegard, 2000)

Mendel's law is the science invented by Gregor Mendel, a pastor who is skilled and trained in biology and mathematics. Based on his biological knowledge he carried out crosses on peas and counted their offspring. His mathematical knowledge is used to manipulate and decrease the "postulate" of inheritance.

Based on the description above, we can see that inheritance is a science discovered by Gregor Mendel. Therefore, a deeper understanding is needed in order to be able to study and know cases of qualitative genetics in fish. 


\section{Genetics}

Genetics is the study of inherited traits in living things from generation to generation. Because the way the transfer of biological information takes place underlies the differences and similarities in traits among individual organisms, it can also be briefly said that genetics is the science of inheritance. This understanding of genetics was influenced by Mendel's findings on patterns of inheritance.

Mendel's work on patterns of inheritance was published in 1866 in the Proceedings of the Brunn Society for Natural History. In 1900 three separate botanists, namely Hugo de Vries in the Netherlands, Carl Correns in Germany and Eric von Tschermak-Seysenegg in Austria, saw evidence of the correctness of Mendel's principles in their respective studies. From that time until approximately the middle of the 20th century, various experiments on the basis of Mendelian principles of crossover dominated research in the field of genetics. This marks the beginning of an era called genetics.

Along with the development of the era, the science of genetics has increasingly developed, even genetics, since the discovery of genes and chromosomes. Genetics progresses towards molecular genetics. Understanding genetics is the study of genes. Genetics is defined as the branch of biology that studies genetic material about its structure, reproduction, work (expression), changes and recombination, its existence in populations, and its engineering.

The discovery of recombinant DNA opened up developments in genetic engineering. Genetic engineering technology provides a lot of hope for us in various fields of need including gene therapy efforts that have been implemented as well as the human genome project. Currently, genetics has been widely applied in everyday life in various fields including agriculture, health, and the pharmaceutical industry (Avise, 2004; Morris, 1999)

\section{Mendel's Law}

Mendel was a pastor who was skilled and trained in biology and mathematics. One day, he crossed the capri and counted the offspring. Mendel explained the inheritance of traits from parents to offspring through mathematical calculations using the peanut plant model (Pisum sativum L.). Mendel explained the inheritance of traits from parents to their descendants through mathematical calculations using the peanut plant model (Pisum sativum L.).

Mendel began his research by selecting peas. Mendel selected and grouped peas with certain characteristics in common. For example, he collected red flowering plants with red flowering plants, he collected white flowering plants with white flowering plants. Furthermore, if the population produces offspring with different characteristics, the different traits are eliminated, and so on until a plant population is found that no longer produces offspring with different traits (called homozygous alleles). Mendel called this plant pure strains, namely plants which, if self-pollinated, would not produce different plants from it. In this case, tall plants will still produce tall plants. Likewise, short plants always produce short plants.

Mendelian peas show simple and clear dominance traits. The presence of a dominant allele means that the trait will be expressed whether it is homozygous or heterozygous. For the recessive form of the trait, expression only occurs in the homozygous form. Dominant allele is written in uppercase, while recessive allele is written as lowercase. Next, Mendel made a cross between these pure lines. In one experiment Mendel crossed a tall pea plant with a short one. By crossing tall pure strains with short pure strains, Mendel got a plant that was all tall. 
Then the tall plants resulting from these crosses are allowed to self-pollinate. It turned out that the offspring showed a ratio (ratio) of tall plants to short plants of 3: 1 .

From his crossover experiments, Mendel produced his law, namely random separation (segregation) and independent assortment (Bierema \& Schwartz, 2016).

\section{Mendel's Law I}

Allele pairs separate (separate) during gamete formation using the meiotic cell division mechanism. Due to this separation, each gamete will consist of a half number of chromosomes ( $\mathrm{n}$ chromosomes). The parent carries only one allele of each gene. During fertilization the gametes originating from the female and male parents create another allele pair.

Mendel did many experiments. He traced several characteristics in the pea plant from which he formulated several hypotheses. Mendel stated that the units of inheritance exist in pairs, separate independently during gamete formation, and one from each parent forms a new pair in the offspring. He crossed pure-strained peas, which have distinctly observable differences in characteristics.

There are several terms associated with Mendel's studies. A monohybrid cross is a cross between two parent plants that differ in only one characteristic. This elder is a pure breed that Mendel has selected. this cross between two pure lines produces F1 offspring.

The result of crossing or the first offspring of the two parents of the pure line is called the first generation or F1. The second generation is an F1 cross crossed with F1 (peas, selffertilization) and is called F2. F1 crosses are also called hybrid crosses. When only one character and two traits are under consideration, it is called a monohybrid. When two characters are being considered, it is called a dihybrid cross.

Dominant traits are exclusive traits that appear in the F1 generation. Recessive traits are traits that are hidden or hidden in the F1 generation. Alleles are various alternative forms of genes, each diploid individual has two, each gamete has one allele for each gene, gamete reunification in the process of fertilization unites alleles from male and female parents to form pairs. Genotype is the actual gene that each individual has or alleles of each individual are contained in the genome. A phenotype is the physical appearance or biochemical activity caused by a genotype. The genotype can be Aa; the phenotype is A, which gives the organism a dominant appearance or function. Genotype aa will have phenotype a which makes the organism have a recessive appearance or function (Marshall et al, 2010).

\section{Mendel's Law II}

Crosses that only involve the inheritance pattern of one kind of trait as did Mendel above are called monohybrids. Mendel performed monohybrid crosses for six other traits. In addition to monohybrid crosses, Mendel also performed dihybrid crosses, which are crosses that involve the inheritance pattern of two kinds of instantaneous traits. This became known as Mendel's law of independent assortment, also known as Mendel's law 2, which states that at the time of gamete formation, the alleles combine freely so that the traits that appear in the offspring vary. Sortation is the combination of genes and alleles that regulate a certain trait. At the time of fertilization, gamete cells that contain single genes will fuse. Mendel 2's law only applies to genes that are located far away. If the two genes are located close to each other, this law does not apply (Rougeux, Bernatchez \& Gagnaire, 2017).

\section{Inheritance}

Inheritance is the traits or traits of living things that are passed down from generation to generation or passed down from parent to offspring. The traits of a living being are inherited through male sex cells and female sex cells. The part of the cell that is responsible for this 
inheritance is in the nucleus of the cell. In the cell nucleus there are chromosomes. Chromosomes are fine threads that function as a factor carrying traits of heredity. In the chromosome there is a substance carrying the trait consisting of chemical compounds called genes. Genes function as determinants of the traits of a living being. Each species has certain characteristics. In the science of genetics, there is a term phenotype, namely inherited traits that can be seen or can be observed, for example skin color, face shape, body size and so on. The phenotype that appears is absolutely determined by genetic factors inherited from the parents. If both parents or one of them, or in their family tree, do not carry this trait in their genes, it is impossible for this trait to arise in the offspring. Genotype is the genetic composition contained by an individual or basic traits that are not visible and their characteristics remain in one individual (Sharma, 2014).

The inheritance of traits is one of the popular theories put forward by George Mendel. Prior to this theory, which was believed to be the theory of inheritance held before Mendel, was the theory of mixed inheritance: a person inherits an even mixture of traits carried by his parents, especially from males because they carry sperm. At that time people still thought that the traits that were passed on to the child came from sperm. This opinion was also disproved by Mendel's research results because the theory put forward by Mendel said that the properties contained in an allele that belonged to each parent were unique. If one parent contains many alleles that are expressed through visible traits (dominant phenotype) then he will inherit these traits, while if the other parent contains many recessive alleles, he will also pass these traits on to his children, so that when the two parents inherit them. These traits for the child, then the nature of the child is not the middle (intermediate) second nature, but a combination of the two, and not a combination of the two equally.

\section{Mendel's Law Deviations}

Mendelian law deviations are deviations that do not come out of Mendel's Law rules, although there is a change in the ratio of $\mathrm{F} 2$ because genes have different properties. So, the phenotype ratio will not be the same as described in Mendel's law. Mendel's law deviation has 5 forms, namely Complementary, polymer, epistasis-hypotasis, cryptomery, and atavism. Complementary is a form of cooperation between two dominant genes that complement each other to create a character. Polymers are interactions between genes that are cumulative (add to each other). Genes interact with each other to influence and produce the same offspring. Epistasis-hypostasis is an event when a dominant gene will mask the influence of another dominant gene that is not an allele. The covered gene is called epistasis, while the covered gene is called hypotasis. Cryptomery is an event that the dominant gene is hidden if it is not paired with other dominant genes. So, if the dominant gene stands alone, then its character will be hidden (cryptos), and the last deviation, namely atavism, is an interaction between genes that results in phyla or offspring with different phenotypes from the parent (Bucchi, 2008).

\section{Methods}

The work procedure carried out in this practicum is by answering the 7 questions given as data by referring to the phenotype table which is influenced by a single autosome gene with complete dominant and qualitative genetic tables from the book Basics of Fish Genetics and Breeding. The steps in the process of working on the problem are determining the parental of each individual, determining the phenotype and gamers of each individual, determining the crossover result in the form of F1, determining the result of crossing in the form of F2, determining the results of the ratio of genotype and phenotype.

\section{Results and Discussion}


$P:$ P $D D \quad>\quad d d \quad ふ$

Table 1. The ratio of F2 genotypes of normal pigmented goldfish to yellow-striped goldfish on the dorsal spine

\begin{tabular}{|l|l|l|}
\hline \multirow{3}{*}{ D } & D & D \\
\hline d & DD & Dd \\
\hline
\end{tabular}

\section{$P: q \mathrm{SnB} \quad>\quad \mathrm{ScB}$ ๙}

Table 2. Ratio of F1 genotypes Normal gray spina guppy mated to guppy spina bent blondi

\begin{tabular}{|l|l|l|}
\hline \multirow{1}{*}{} & Scb & Scb \\
\hline SnB & SnScBb & SnScBb \\
\hline SnB & SnScBb & SnScBb \\
\hline
\end{tabular}

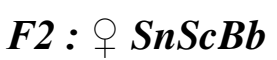

$>\quad S n S c B b$

Table 3. The ratio of F2 genotypes Normal gray spina guppy fish is mated to guppy spina bent blondi

\begin{tabular}{|l|l|l|l|l|}
\hline প/ð & SnB & ScB & Snb & Scb \\
\hline SnB & SnSnBB & SnScBB & SnSnBb & SnScBb \\
\hline ScB & SnScBB & ScScBB & SnScBb & ScScBb \\
\hline Snb & SnSnBb & SnScBb & SnSnbb & SnScbb \\
\hline Scb & SnScBb & ScScBb & ScSnbb & ScScbb \\
\hline
\end{tabular}

$\boldsymbol{P}:$ ㅇ $\boldsymbol{V} \boldsymbol{V} \quad<\quad \boldsymbol{v} \quad \widehat{\jmath}$

Table 4. F1 genotype ratios of dark blue betta fish are mated to green

\begin{tabular}{|l|l|l|}
\hline \hline$\hat{O}$ & $\mathrm{~V}$ & $\mathrm{~V}$ \\
\hline $\mathrm{v}$ & $\mathrm{Vv}$ & $\mathrm{Vv}$ \\
\hline $\mathrm{v}$ & $\mathrm{Vv}$ & $\mathrm{Vv}$ \\
\hline
\end{tabular}

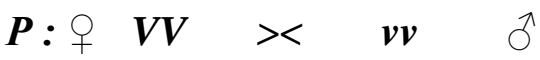

Table 5. F2 genotype ratio of shiny blue betta fish to green betta fish

\begin{tabular}{|l|l|l|}
\hline J人 & V & v \\
\hline $\mathrm{V}$ & $\mathrm{VV}$ & $\mathrm{Vv}$ \\
\hline
\end{tabular}






$P: \circ \quad G^{\prime} G^{\prime}><\quad G^{\prime} \boldsymbol{G} \lesssim$

Table 5. F1 genotype ratio of golden rainbow trout spawned with rainbow trout palomino

\begin{tabular}{|l|l|l|}
\hline$\hat{O}^{\prime}$ & G' $^{\prime}$ & G' \\
\hline G' & G'G' $^{\prime}$ & G'G' \\
\hline G & G'G & G'G \\
\hline
\end{tabular}

\section{P: 우 GgCucu $>$ Ggcucu}

Table 6. F1 genotype ratio GgCucu guppies mated to Ggcucu guppies

\begin{tabular}{|l|l|l|l|l|}
\hline Я/ふ & Gcu & Gcu & gcu & gcu \\
\hline GCu & GGCucu & GGCucu & GgCucu & GgCucu \\
\hline Gcu & GGcucu & GGcucu & Ggcucu & Ggcucu \\
\hline gCu & GgCucu & GgCucu & ggCucu & ggCucu \\
\hline gcu & Ggcucu & Ggcucu & ggcucu & ggcucu \\
\hline
\end{tabular}

Practicum has been carried out by calculating the results of crosses in determining cases that occur in fish qualitative genetics. By working on and answering the questions that have been given as material in this practicum, we will know how the crossing of a fish species occurs, and can determine the type of fish from competition and determine the results that occur in fish qualitative genetics.

According to Palmer et al, (2004), qualitative genetics is one of the diversity in individuals caused by the action of only a few pairs of genes that affect qualitative traits/phenotypes. In fish as well as other animals, qualitative inheritance results in several classes of traits that are discrete, or can be categorized under a variety of different traits.

From the calculation in the case of qualitative genetics, the number one result shows that normal pigmented goldfish are mated with yellow-striped goldfish on the dorsal spine to produce $100 \%$ fish with yellow lines on the dorsal spine. It is known that the yellow striped goldfish on the dorsal spine is dominant over other traits, so that the percentage of the dominant phenotype is $100 \%$ while the recessive phenotype percentage is $0 \%$.

\section{Conclusion}

Genetics is the study of the inheritance of traits from parent to offspring and following certain patterns. The laws of genetics are the laws of segregation and random assortment Fish genetics is the science of biology that studies the genetic information of the parent offspring of a fish organism. Character inheritance or heredity is the inheritance of traits from parents to their children (offspring). Mendel's theory can explain the various observations that the theory of mixed heredity cannot explain and can be used well as a framework for understanding the mechanism of inheritance in a more detailed and detailed manner. There are several kinds of events that are categorized as apparent deviations from Mendel's law, namely atavism (interaction), criticism, epistasis and hypostasis. 


\section{References}

Ashwell, M. S., Van Tassell, C. P., \& Sonstegard, T. S. (2000). The cooperative dairy DNA repository: a new resource for quantitative trait loci detection and verification. In Proceedings of the 8th Plant and Animal Genome Conference, San Diego, CA.

Avise, J. C. (2004). The hope, hype, and reality of genetic engineering: Remarkable stories from agriculture, industry, medicine, and the environment. Oxford University Press.

Bierema, A., \& Schwartz, R. (2016). A Card Game for Teaching Mendel's Laws, Meiosis, and Punnett Squares: Learning from the Fruit Fly. The Science Teacher, 83(8), 39.

Bucchi, M. (2008). Of deficits, deviations and dialogues: Theories of public communication of science. Handbook of public communication of science and technology, 57, 76.

Chabris, C. F., Lee, J. J., Cesarini, D., Benjamin, D. J., \& Laibson, D. I. (2015). The fourth law of behavior genetics. Current directions in psychological science, 24(4), 304312.

Marshall, D. J., Monro, K., Bode, M., Keough, M. J., \& Swearer, S. (2010). Phenotype-environment mismatches reduce connectivity in the sea. Ecology letters, 13(1), 128-140.

Martínez-Romero, E., \& Caballero-Mellado, J. (1996). Rhizobium phylogenies and bacterial genetic diversity. Critical Reviews in Plant Sciences, 15(2), 113-140.

Morris, J. B. (1999). Legume genetic resources with novel value added industrial and pharmaceutical use. Perspectives on new crops and new uses, 196-201.

Morange, P. E., Suchon, P., \& Trégouët, D. A. (2015). Genetics of Venous Thrombosis: update in 2015. Thrombosis and haemostasis, 114(11), 910-919.

Palmer, R. G., Pfeiffer, T. W., Buss, G. R., \& Kilen, T. C. (2004). Qualitative genetics. Soybeans: improvement, production, and uses, 16, 137-233.

Rougeux, C., Bernatchez, L., \& Gagnaire, P. A. (2017). Modeling the multiple facets of speciation-with-gene-flow toward inferring the divergence history of lake whitefish species pairs (Coregonus clupeaformis). Genome biology and evolution, 9(8), 20572074.

Sharma, S., Kaur, M., Goyal, R., \& Gill, B. S. (2014). Physical characteristics and nutritional composition of some new soybean (Glycine max (L.) Merrill) genotypes. Journal of food science and technology, 51(3), 551-557.

Snustad, D. P., \& Simmons, M. J. (2015). Principles of genetics. John Wiley \& Sons. 